Article

\title{
Tuning of Proanthocyanidin Extract's Composition through Quaternary Eutectic Solvents Extraction
}

\author{
Rodrigo T. Neto $^{1}{ }^{(}$, Sónia A. O. Santos ${ }^{1}\left(\mathbb{D}\right.$, Joana Oliveira ${ }^{2}\left(\mathbb{C}\right.$ and Armando J. D. Silvestre ${ }^{1, *(\mathbb{C}}$ \\ 1 CICECO-Aveiro Institute of Materials, Chemistry Department, University of Aveiro, Campus de Santiago, \\ 3810-193 Aveiro, Portugal; rtneto@ua.pt (R.T.N.); santos.sonia@ua.pt (S.A.O.S.) \\ 2 REQUIMTE_Laboratório Associado para a Química Verde, Departamento de Química e Bioquímica, \\ Faculdade de Ciências, Universidade do Porto, Rua do Campo Alegre, 687, 4169-007 Porto, Portugal; \\ jsoliveira@fc.up.pt \\ * Correspondence: armsil@ua.pt; Tel.: +351-234-370-711; Fax: +351-234-370-084
}

Received: 17 October 2020; Accepted: 9 November 2020; Published: 13 November 2020

\begin{abstract}
Currently available proanthocyanidins extraction methods rely on dedicated crops and have low specificity and yield which limits their industrial application. Consequently, the development of novel methodologies and the use of sustainable sources is of great importance. Eutectic solvents have been proposed has good alternatives for conventional solvents due to their low price, easiness of preparation, biocompatibility and ability of being custom made to a specific application. Herein the effective extraction of proanthocyanidins from grape pomace and the possibility of tuning the extract's characteristics such as mean degree of polymerization and galloylation percentage is explored by means of varying the composition of a quaternary eutectic solvent composed by choline chloride, glycerol, ethanol and water. It was found that mean degree of polymerization values can vary from 6.0 to 7.37 and galloylation percentage can vary from $32.5 \%$ to $47.1 \%$ while maintaining extraction yield above $72.2 \mathrm{mg}$ of proanthocyanidins per $\mathrm{g}$ of biomass. Furthermore, the increase of temperature up to $100^{\circ} \mathrm{C}$ has showed a significant effect on the extraction yield being possible to increase it by $238 \%$ when compared to the conventional extraction method.
\end{abstract}

Keywords: proanthocyanidin; eutectic solvents; extraction optimization; degree of polymerization; galloylation percentage

\section{Introduction}

Proanthocyanidins (PACs), also known as condensed tannins, are secondary metabolites ubiquitous to all plant kingdom [1]. PACs are polymeric phenolic compounds comprising of flavan-3-ols monomers such as catechin and its derivatives (Figure 1). PACs are believed to play essentially two roles in plants, namely, as defense against microbial pathogens [2,3] and as deterrents against herbivory $[4,5]$. The mechanism by which PACs are able to achieve these functions come from their complexation ability of metal ions in the former case [6] and protein aggregation [7] and enzyme inhibition [8] in the latter.

Currently, PACs are mostly used in the production of high-end leather [9] and wood agglomerates [10] as well as in wine maturation [11]. More recently, PACs have also been proposed as viable alternatives for the replacement of synthetic food grade antioxidant [12,13] and antimicrobial [14] agents. In addition, PACs have also been reported for their beneficial properties for human health, more specifically, in the inhibition of enzymes related to high blood pressure [15] and carbohydrate metabolism [16-18], as well as anti-cancer $[19,20]$ and anti-inflammatory activities [21]. 
a)

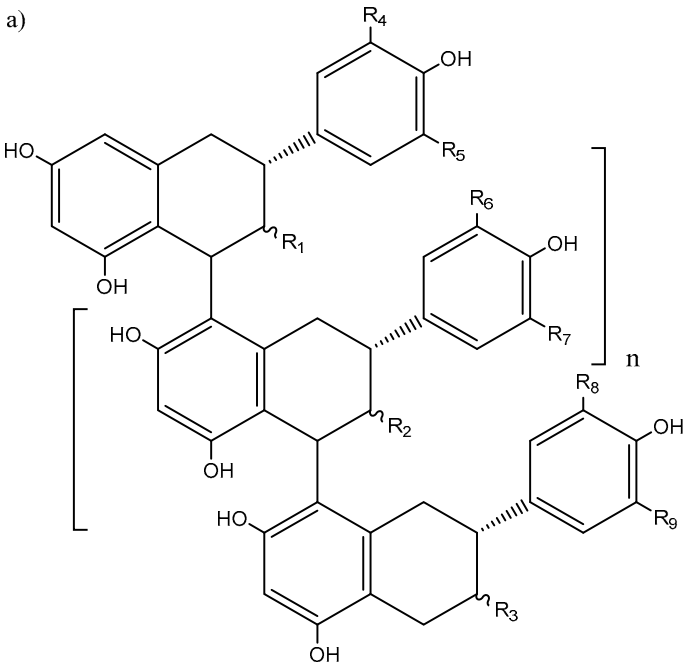

b)<smiles>O=C([O-])c1cc(O)c(O)c(O)c1</smiles>

Figure 1. General molecular structure of (a) B-type proanthocyanidins (R1, R2, R3 = OH or (b) gallate units; R4, R5, R6, R7, R8, R9 = H or OH).

The most common source of PACs for commercial use is Quebracho (Schinopsis lorentzii) heartwood which can have PACs contents up to $43 \%$ (w/w) [22]. Nevertheless, Quebracho trees are only present in South America and their use as raw material implies the transportation of the resulting extract across the globe. In addition, PACs obtained from Quebracho come from a dedicated crop, specifically grown for that purpose which is not the optimal use of water and arable land in terms of economic value since they can be found in high concentration in agroforestry by-products [23].

Agroforestry by-products could be used as alternative raw materials for the obtention of PACs which would allow for a more sustainable and efficient process as far as limited resources, such as water and arable land, are concerned. In addition, this approach is also valuable for the decrease of overall amount of waste as described by the European commission directive (2008/98/EC) [24] as well as to increase economic value of agroforestry by-products such as fruit peels [25] and wood barks [26] by taking advantage of their high PAC content as summarized elsewhere [23].

Grape pomace in particular, is a by-product of wine production which has been the subject of several dedicated reviews that explored its potential as a source of antimicrobial agents [27], human health promoter [28] and animal nutrition [29] in part due to its high PACs content.

Wine industry is one of the most important agricultural activities worldwide and produced 292 million hL of wine and 44 million tons of grape for that purpose in 2018 [30], which led to the production of approximately 11 million tons of grape pomace (considering that $1 \mathrm{~kg}$ of fresh grapes results in $0.25 \mathrm{~kg}$ of pomace). Currently, grape pomace has little to no commercial value and often represents additional costs for the producer related to their disposal.

Presently, the industrial use of PAC extracts is often limited by their high price, especially when compared to the available synthetic (yet more harmful) alternatives. In general, these extracts are obtained through the use of a hot pressurized sulfite aqueous solution [31]. Unfortunately, the amount of unextracted PACs can be as high as $62.5 \%$ in white grapes [32] and $62.3 \%$ in Norway spruce bark [33], resulting in a low yield process and a final extract that is mostly composed of PACs with lower degree of polymerization that are not as effective as the ones with higher degree of polymerization. Additionally, in order to achieve the intended mean degree of polymerization (mDP) further downstream processing is needed, making its final price prohibitive for most applications.

Therefore, to further increase the extraction efficiency and added value of PACs extracts it is essential to combine the use of by-products rich in these compounds with innovative extraction procedures. Some innovations come from the combination of ultrasound assisted or microwave assisted extraction 
with aqueous mixtures of organic solvents as discussed elsewhere [23]. Nevertheless, these approaches still rely on the use of harmful organic solvents and new greener alternatives must be found.

More recently, eutectic solvents (ESs) have been proposed as very promising media for the extraction of bioactive compounds from biomass [34]. ESs can be described as a mixture of two compounds (hydrogen bond acceptor (HBA) and hydrogen bond donor (HBD)) that have a decreased melting point when compared to the individual components and were first proposed as a solvent in the context of deep eutectic solvents (DES) by Abbot et al. [35]. These differentiate from ESs by the fact that the decrease in the melting point is greater than what would be expected in an ideal mixture [36]. (D)ESs are characterized by their biocompatibility, low toxicity, easiness of preparation and ability of being custom made to a specific application.

The application of ESs in the extraction of PACs is still limited, however they have been studied in the extraction of PACs from Gingko biloba leaves with satisfactory results [37]. A mixture of choline chloride and malonic acid at a molar proportion of $1: 2$ with $55 \%(\mathrm{~m} / \mathrm{m})$ of water at $65{ }^{\circ} \mathrm{C}$ was used and an improvement of $67 \%$ when compared with aqueous $70 \%$ (v/v) acetone was obtained.

Due to (D)ESs high viscosity, water addition is frequently employed, as shown in the example presented before [37]. Nevertheless, the use of ethanol for that purpose, a solvent that is naturally sourced and safe for human consumption, is still unexplored. In addition, it is also a more effective solvent at room temperature on the extraction of PACs [38] when compared to water and therefore, could represent a valuable option in the development of new solvent systems.

One aspect that is frequently overlooked in the extraction of PACs is the possibility of tuning the extract's final characteristics, such as $\mathrm{mDP}$ and galloylation percentage (\%Gal). mDP has been shown to positively correlate with the inhibition of $\alpha$-glucosidase and pancreatic lipase [39], cellular antioxidant [40] and anti-inflammatory [21] activities and protein precipitation [41,42]. \%Gal has been shown to influence antiviral activity [43] and protein precipitation [44] as well. In addition, both characteristics appear to play an important role in antiproliferation of human colon cancer cells [45].

Herein, the use of mixtures of ethanol, water and ESs in the obtention of PACs from white grape pomace was explored for the first time. Several combinations of HBAs and HBDs were screened and the best candidate was selected. The effects of mass fraction of HBA, HBD, water and ethanol were optimized using response surface methodology (RSM) to determine the best solvent composition in the tuning of the final extract characteristics. A similar approach was used to optimize the extraction conditions of PACs, namely the temperature, solid:liquid ratio and extraction time. PACs yield $\left(Y_{\text {PAC }}\right)$ was quantified using the acid butanol method and the $\mathrm{mDP}$ and $\% \mathrm{Gal}$ were determined by phloroglucinolysis.

\section{Materials and Methods}

\subsection{Reagents and Equipment}

All reagents and solvents were used as received without further processing. Acetone, concentrated hydrochloric acid, phloroglucinol, sodium sulfite, glycerol, ammonium iron (III) sulfate dodecahydrate and (+)-catechin hydrate were purchased from Sigma-Aldrich (St. Louis, MO, USA). Methanol, dichloromethane, absolute ethanol, 1-butanol, ascorbic acid and anhydrous sodium acetate were purchased from Fisher Scientific (Hampton, VA, USA). Choline chloride, betaine, proline and (D)-glucose were purchased from Acros Organics (Waltham, MA, USA). Urea and DL-malic acid were purchased from VWR (Radnor, PA, USA). Toyopearl HW-40S resin was acquired from Tosoh (Tokyo, Japan). HPLC-grade water, acetonitrile and formic acid were acquired from Fisher Scientific.

The High-Performance Liquid Chromatography (HPLC) system was an Accela from Fisher Scientific with an Accela 600 LC pump and an Accela $80 \mathrm{~Hz}$ Diode-Array detector (DAD). Chromatographic separation was carried out with a Hypersil GOLD C18 $(2.1 \times 100 \mathrm{~mm}$ with $1.9 \mu \mathrm{m}$ particle size) column from Thermo Scientific. The MS system used for compound identification was a LCQ Fleet ion trap mass spectrometer from Thermo Finnigan with an electrospray ionization (ESI) 
source. Data acquisition was performed by using the Xcalibur data system from Thermo Finnigan (Waltham, MA, USA).

\subsection{Grape Pomace Preparation}

White grape pomace was obtained from a mixture of grape varieties from the Douro region in Portugal and was collected during the 2019 harvest after pressing for must extraction. The grape pomace was then kept frozen at $-20^{\circ} \mathrm{C}$ until freeze-drying after which it was kept tightly closed at room temperature protected from light until use.

\subsection{Isolation of Grape Proanthocyanidins}

PACs were isolated from grape pomace to use as standard for colorimetric quantification following the method described by Alwerdt et al. [46] with slight modifications. Briefly, freeze-dried grape pomace was firstly defatted with dichloromethane by Soxhlet extraction for $6 \mathrm{~h}$. The defatted pomace was then extracted three times with aqueous $70 \%(\mathrm{v} / \mathrm{v})$ acetone for $2 \mathrm{~h}$ at room temperature under continuous agitation at $100 \mathrm{rpm}$ and with $10 \%(\mathrm{~m} / \mathrm{m})$ of biomass. After extraction, the supernatants were pooled together and the solvent was removed in a rotary evaporator at $40{ }^{\circ} \mathrm{C}$. The crude dry residue was resuspended in a minimum amount of distilled water, freeze-dried and kept in a desiccator until further use. $2 \mathrm{~g}$ of the crude dry extract were dissolved in $20 \mathrm{~mL}$ of methanol and after vortexing thoroughly for $5 \mathrm{~min}$, the suspension was centrifuged for $10 \mathrm{~min}$ at $6000 \mathrm{rpm}$. The supernatant was then loaded into a glass column with an internal diameter of $16 \mathrm{~mm}$ packed with $100 \mathrm{~mm}$ of Toyopearl HW-40 resin, previously equilibrated with methanol. The flow was kept at $1.5 \mathrm{~mL} / \mathrm{min}$ with the extract being firstly washed with $300 \mathrm{~mL}$ of methanol followed by the elution of the fraction of interest with $250 \mathrm{~mL}$ of methanol with $30 \%(\mathrm{v} / \mathrm{v})$ acetone. The solvent was completely removed from this fraction in a rotary evaporator at $40^{\circ} \mathrm{C}$, the dry residue was resuspended in a minimum amount of distilled water, freeze-dried and kept in a desiccator until further use.

\subsection{Quantification of Proanthocyanidins Content by Acid Butanol Assay}

PACs quantification was performed by the acid butanol assay as described by Porter et al. [47] with some modifications. Briefly, $82.5 \mu \mathrm{L}$ of a methanolic solution containing a known amount of PACs extract was transferred into pressure and temperature resistant tubes and mixed with $500 \mu \mathrm{L}$ of butanol reagent (butanol with 5\% (v/v) of concentrated hydrochloric acid) and $18 \mu \mathrm{L}$ of ammonium iron (III) sulfate dodecahydrate solution $(20 \mathrm{mg} / \mathrm{mL}$ prepared in aqueous hydrochloric acid $(2 \mathrm{M})$ ). The mixture was incubated at $100{ }^{\circ} \mathrm{C}$ for $50 \mathrm{~min}$ and after cooling the absorbance at $520 \mathrm{~nm}$ was measured. The quantification was made using the purified PACs described previously as standard.

\subsection{Determination of Proanthocyanidins Mean Degree of Polymerization and Galloylation Percentage by Phloroglucinolysis}

The determinations of PAC's mDP and \%Gal were made following the Kennedy et al. [48] phloroglucinolysis method with slight modifications. Briefly, samples containing approximately $10 \mathrm{mg}$ of PACs were dissolved in $1.0 \mathrm{~mL}$ of a freshly prepared methanol solution containing $50 \mathrm{~g} / \mathrm{L}$ of phloroglucinol, $10 \mathrm{~g} / \mathrm{L}$ of ascorbic acid and $0.1 \mathrm{M}$ of hydrochloric acid. After spinning down for removal of insolubilized material, $400 \mu \mathrm{L}$ of the mixtures were transferred to pressure resistant vials and were incubated at $50{ }^{\circ} \mathrm{C}$ for $1 \mathrm{~h}$ after which the reaction was stopped by adding $2 \mathrm{~mL}$ of $40 \mathrm{mM}$ sodium acetate aqueous solution. The depolymerization products were quantified by HPLC with eluents A (acetonitrile with $0.1 \%(\mathrm{v} / \mathrm{v})$ formic acid) and B (99\% (v/v) water and $1 \%(\mathrm{v} / \mathrm{v})$ of acetonitrile with $0.1 \%(\mathrm{v} / \mathrm{v})$ of formic acid) and were filtered under vacuum with $0.2 \mu \mathrm{m}$ pore before adding formic acid. The elution program started with $99 \%(\mathrm{v} / \mathrm{v})$ of B for $3 \mathrm{~min}$, decreased to $69 \%(\mathrm{v} / \mathrm{v})$ over $27 \mathrm{~min}$ and to $0 \%(\mathrm{v} / \mathrm{v}$ ) over $2 \mathrm{~min}$, followed by an increase to $99 \%$ (v/v) over $4 \mathrm{~min}$ that were kept for $4 \mathrm{~min}$. Peak identification was made by ESI-MS operated in the negative ion mode with operational conditions described elsewhere [49]. Quantification of phloroglucinolysis products was made with a calibration 
curve of $( \pm)$-catechin aqueous solution with concentrations ranging from 1 to $250 \mu \mathrm{g} / \mathrm{mL}$. The mDP was calculated by dividing the sum of terminal and extension units by the sum of terminal units and the \%Gal was calculated by dividing the sum of galloylated units by the sum of all units.

\subsection{Extraction with Conventional Solvents}

The efficiency of conventional solvents, namely, hot water (HWE), hot $2 \%(\mathrm{~m} / \mathrm{m})$ sodium sulfite solution (HSE), aqueous $70 \%(\mathrm{v} / \mathrm{v})$ acetone (AAE), aqueous $\mathrm{x} \%(\mathrm{~m} / \mathrm{m})$ ethanol (AEEx; $x=15,30,50,70)$ was assayed in a single step solid-liquid extraction with $10 \%(\mathrm{~m} / \mathrm{m})$ of grape pomace. HWE and HSE were performed at $110^{\circ} \mathrm{C}$ for $2 \mathrm{~h}$ while AAE and AEEx were performed at $30{ }^{\circ} \mathrm{C}$ for $4 \mathrm{~h}$ under continuous agitation at $100 \mathrm{rpm}$ after which suspensions were centrifuged at 10,000 rpm for $10 \mathrm{~min}$ and the supernatants collected and stored at $-20{ }^{\circ} \mathrm{C}$ until characterization.

\subsection{Preparation of Mixtures of Eutectic Solvents and Water/Water:Ethanol}

ESs mixtures were prepared by adding the appropriate mass of each component to a flask with a magnetic bar and placing it in a magnetic stirrer at room temperature or at $40^{\circ} \mathrm{C}$, if needed, until a continuous liquid phase was obtained.

\subsection{Screening of Hydrogen Bond Acceptor and Hydrogen Bond Donor Combination}

Different combinations of HBAs (choline chloride $(\mathrm{ChCl})$, betaine (Bet), proline (Pro)) and HBDs (urea (Ur), malic acid (MalA), glucose (Glu) and glycerol (Glyc)) were screened at a 3:1 molar proportion, for $4 \mathrm{~h}$ at $30{ }^{\circ} \mathrm{C}$ with $10 \%(\mathrm{~m} / \mathrm{m})$ of grape pomace under continuous stirring at $100 \mathrm{rpm}$. The ES content was varied from $25 \%$ to $75 \%$ and the remainder was composed either by water or water:ethanol (1:1) mixture. After extraction, mixtures were centrifuged at $10,000 \times g \mathrm{rpm}$ for $10 \mathrm{~min}$, the supernatants were recovered and store at $-20^{\circ} \mathrm{C}$ until characterization.

\subsection{Determination of Optimal Solvent Composition}

After a preliminary selection of the most suitable ES, namely $\mathrm{ChCl}$ :Glyc and having verified the impact of the presence of water and ethanol, the optimal extraction media composition was determined using RSM for mixtures using D-optimal design in Expert Design v12 from StateEase (Minneapolis, MN, USA). The experimental design consisted of 20 experimental points in which the assayed variables were the mass fractions of choline chloride $\left(x_{\mathrm{ChCl}}\right)$, glycerol $\left(x_{\mathrm{Glyc}}\right)$, water $\left(x_{\mathrm{water}}\right)$ and ethanol $\left(x_{\mathrm{EtOH}}\right)$ and the experimental constraints were $x_{\mathrm{ChCl}}<0.7, x_{\mathrm{Glyc}}<0.95,0.05<x_{\text {water }}<0.5, x_{\mathrm{EtOH}}<0.4$ and $x_{\mathrm{ChCl}}+x_{\mathrm{EtOH}}<0.7$. Experimental solvent compositions are detailed in Table A1 and all extractions were performed at $30{ }^{\circ} \mathrm{C}$ under continuous agitation at $100 \mathrm{rpm}$ with $\left.10 \% \mathrm{~m} / \mathrm{m}\right)$ of grape pomace. Validation runs were performed in triplicate for the solvent compositions that resulted in the best $Y_{\text {PAC }}$ and best \%Gal.

\subsection{Determination of Optimal Extraction Conditions}

Optimal extraction conditions were determined using RSM with Box-Behnken Design in Expert Design v12 from StateEase (Minneapolis, MN, USA). The experimental design consisted of 15 experimental points in which the assayed variables were temperature (temp), biomass percentage (\%BM) and extraction time (time) with minimum (-1) and maximum (1) values ranging from 70 to $110{ }^{\circ} \mathrm{C}, 5$ to $20 \%(\mathrm{~m} / \mathrm{m})$ and 1 to $5 \mathrm{~h}$, respectively. Experimental conditions for each run are detailed in Table A2. All extractions were performed under continuous agitation at $100 \mathrm{rpm}$ and solvent composition was the one from which the highest $Y_{\text {PAC }}$ values were obtained in the previous section. Validation runs were performed in triplicate for the experimental conditions that resulted in the best $Y_{\mathrm{PAC}}$ and best \%Gal. 


\section{Results}

\subsection{Proanthocyanidins Extraction with Conventional Solvents}

The extraction yields obtained with the different conventional solvents, hot water extraction (HWE), hot sulfite extraction (HSE), aqueous acetone extraction (AAE) and aqueous ethanol extraction (AEEx) and the respective $\mathrm{mDP}$ and $\% \mathrm{Gal}$ in a single step solid-liquid extraction are shown in Figure 2 and Table A3.
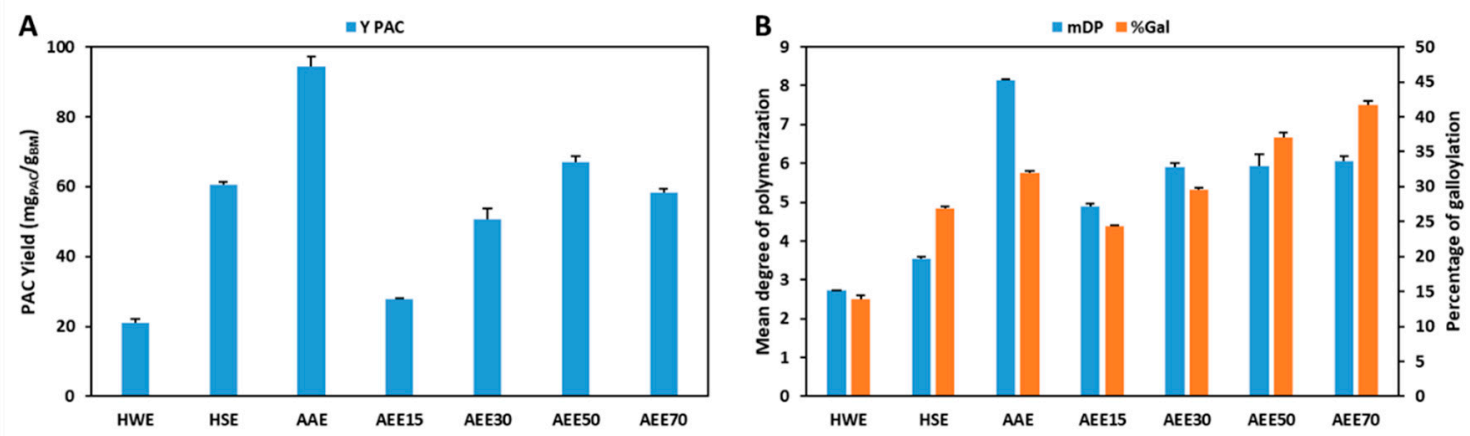

Figure 2. Comparison of $Y_{\mathrm{PAC}}(\mathrm{A})$ and $\mathrm{mDP}$ and \%Gal (B) obtained with conventional solvents (HWE-hot water extraction; HSE-hot sulfite extraction; AAE-aqueous acetone extraction; AEEx-aqueous ethanol extraction).

As expected, the best results were obtained in AAE as far as yield ( $\left.94.4 \mathrm{mg}_{\mathrm{PAC}} / \mathrm{g}_{\mathrm{BM}}\right)$ and $\mathrm{mDP}(8.1)$ are concerned which further supports the use of aqueous acetone as a reference solvent for PACs extraction at a laboratory level. Despite being a very efficient extraction solvent, at a concentration of $70 \%(\mathrm{v} / \mathrm{v})$ acetone it presents several risks for the operators and to the environment, requiring additional protective measures that represent increased operational costs.

Nevertheless, the results presented here also demonstrate that the use of ethanol:water mixtures with an ethanol content higher than $50 \%(\mathrm{~m} / \mathrm{m})$ enables the obtention of PACs extracts with higher $\%$ Gal (37.1\%) when compared with the results obtained with AAE (31.9\%). Furthermore, a direct correlation is verified between the ethanol content in the extraction mixture and \%Gal that reaches its maximum value at $70 \%(\mathrm{~m} / \mathrm{m})$ ethanol with $41.6 \%$ of galloylated monomers. This trend was not verified for yield and $\mathrm{mDP}$ which show maximum values at $50 \%(\mathrm{~m} / \mathrm{m})$ ethanol $\left(67.1 \mathrm{mg}\right.$ PAC/ $\left./ \mathrm{g}_{\mathrm{BM}}\right)$ and a constant value above $30 \%(\mathrm{~m} / \mathrm{m})$ ethanol (5.9), respectively.

As far as the use of mixtures of ethanol and water is concerned, it is clear that despite the fact that the variation of ethanol allows a good control in the \%Gal without affecting $\mathrm{mDP}$ considerably, this occurs in detriment of extraction yield for ethanol percentages higher than $50 \%(\mathrm{~m} / \mathrm{m})$ which indicates that AEE is not an efficient system by itself for the extraction of PACs.

In terms of organic solvent free extractions, the use of pure water with showed low yield $\left(21.0 \mathrm{mg}_{\mathrm{PAC}} / \mathrm{g}_{\mathrm{BM}}\right), \mathrm{mDP}(2.7)$ and $\% \mathrm{Gal}(13.8 \%)$ which were improved with the addition of sodium sulfite, to values of $60.4 \mathrm{mg}$ PAC $/ \mathrm{g}_{\mathrm{BM}}, 3.5 \%$ and $26.9 \%$, respectively. Nevertheless, although being possible to obtain comparable $Y_{\mathrm{PAC}}, \mathrm{mDP}$ and $\% \mathrm{Gal}$, these values are still considerably lower than the ones obtained with mixtures of organic solvents and water.

\subsection{Screening of Hydrogen Bond Acceptor and Hydrogen Bond Donor Combination}

HBA and HBD candidates were first selected based on their benign character and previous referencing in scientific literature for biomass processing [37,50-52]. Choline chloride ( $\mathrm{ChCl})$, betaine (Bet) and proline (Pro) were selected as HBAs while urea (Ur), malic acid (MalA), glucose (Glu) and glycerol (Glyc) were selected as HBDs. In a preliminary study (data not shown), it was concluded that mixtures containing Bet and Pro based ESs led to considerably lower extraction yields when compared to $\mathrm{ChCl}$ and therefore, their application in PACs extraction was not further explored. 
The effect of different HBDs in combination with $\mathrm{ChCl}$ on the $Y_{\mathrm{PAC}}$ is compared in Figure $3 \mathrm{~A}$ and it is possible to observe that at a concentration of $75 \%$ of $\mathrm{ES}$, the best results were obtained with Ur and MalA (80.7 and $81.4 \mathrm{mg}_{\mathrm{PAC}} / \mathrm{g}_{\mathrm{BM}}$, respectively) followed by Glu and Glyc (65.9 and 66.4, respectively). Additionally, if the water content is increased to $75 \%$, a decrease in $Y_{\text {PAC }}$ of approximately $50 \%$ is observed for all candidates except for MalA which only decreases 30\%. Nevertheless, this effect can be overcome if a mixture of water and ethanol is used instead of adding only water to ESs. This is especially true for ESs containing Glu and Glyc (75.0 and $76.2 \mathrm{mg}_{\mathrm{PAC}} / \mathrm{g}_{\mathrm{BM}}$, respectively) which led to yields higher than the ones obtained with 75\% ES and less accentuated for Ur and MalA (72.3 and $85.0 \mathrm{mg}_{\mathrm{PAC}} / \mathrm{g}_{\mathrm{BM}}$, respectively).

\section{A} Water $₫$ Water/ethanol (1:1)

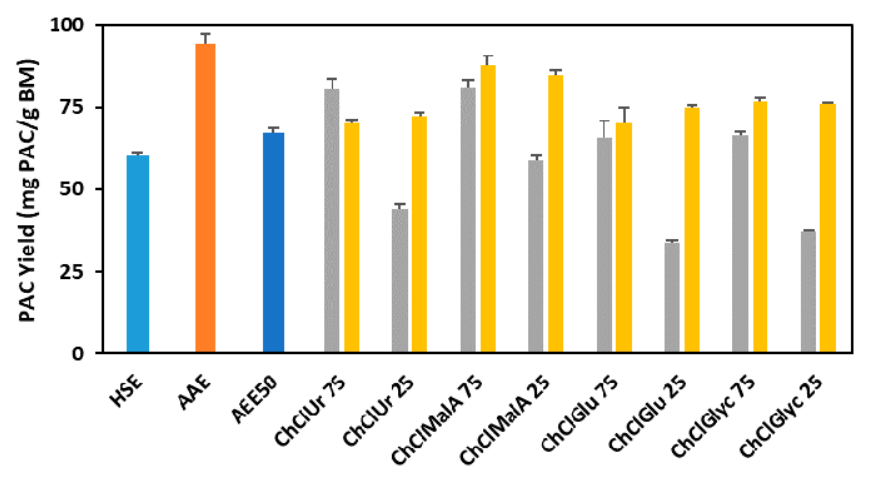

B Water $\square$ Water/ethanol (1:1)

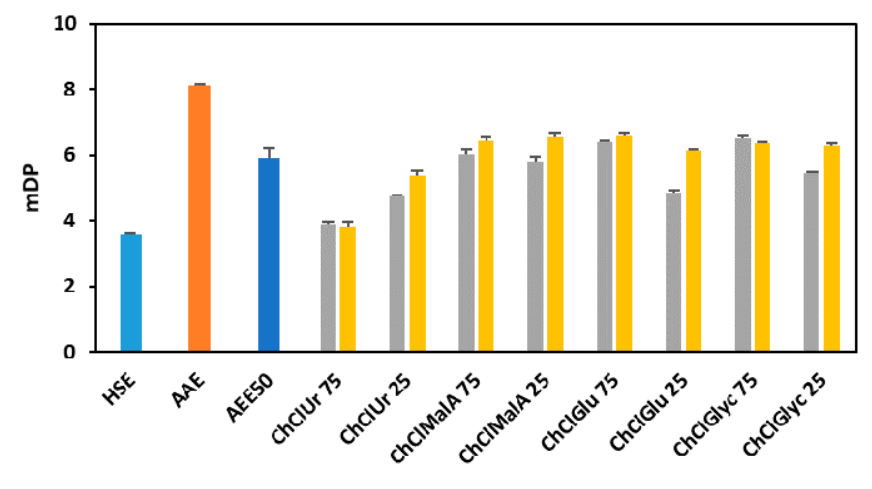

C $\varpi$ Water $\square$ Water/ethanol (1:1)

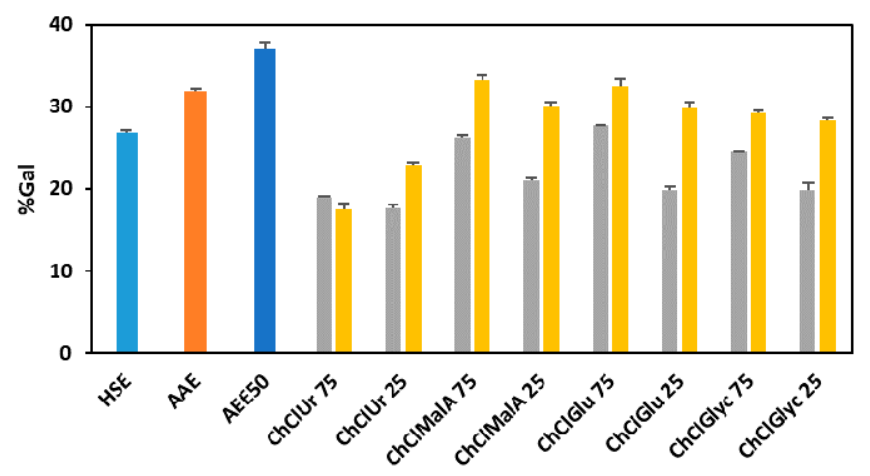

Figure 3. Comparison of $Y_{\mathrm{PAC}}(\mathbf{A}), \mathrm{mDP}(\mathbf{B})$ and $\% \mathrm{Gal}(\mathbf{C})$ between conventional solvents (HSE, AAE and AEE50) and mixtures of ES with water or water and ethanol. ( $\mathrm{ChCl}$-choline chloride; $\mathrm{Ur}$ - urea; MalA—malic acid; Glu—glucose; Glyc-glycerol; the number following ES represents its percentage). 
In terms of $\mathrm{mDP}$ (Figure 3B), the best results were obtained with Glu and Glyc (6.4 and 6.5, respectively) followed by MalA (6.0) and Ur (3.9). As for $Y_{\mathrm{PAC}}$, the increase on the water content has a negative effect on the overall results, except for Ur and the addition of ethanol overcomes the reduction in the mDP. Similar observations were made for \%Gal (Figure 3C) concerning the effect of HBD and water content. Nevertheless, the addition of ethanol has a more noticeable effect on the final result when compared to the effect on $\mathrm{mDP}$ which is corroborated by the results depicted in Figure 2B.

\subsection{Determination of Optimal Solvent Composition}

From the previous section, $\mathrm{ChCl}$ and Glyc mixtures were chosen as the best candidates for solvent composition optimization due to low price, chemical and microbiological stability. Additionally, water and ethanol content were also considered due to their effect on solvent viscosity reduction and \%Gal content tuning, respectively.

Consequently, a 20-run mixture RSM experiment was performed where $x_{\mathrm{ChCl}}, x_{\mathrm{Glyc}}, x_{\mathrm{water}}$ and $x_{\mathrm{EtOH}}$ were varied as specified in Table A1 and $Y_{\mathrm{PAC}}, \mathrm{mDP}$ and $\% \mathrm{Gal}$ were determined.

The resulting polynomials are presented in Equations (1)-(3) for $Y_{\mathrm{PAC}}, \mathrm{mDP}$ and \%Gal, respectively, from which contour plots were derived and presented in Figure 4 where $x_{\mathrm{ChCl}}, x_{\mathrm{Glyc}}$ and $x_{\mathrm{water}}$ are varied and $x_{\mathrm{EtOH}}$ is kept constant at 0.2 .

$$
\begin{aligned}
& Y_{\mathrm{PAC}}=72.2 x_{\mathrm{ChCl}}+58.3 x_{\mathrm{Glyc}}-13.8 x_{\mathrm{water}}+8.13 x_{\mathrm{EtOH}}-38.0 x_{\mathrm{ChCl}} x_{\mathrm{Glyc}} \\
&+145 x_{\mathrm{ChCl}} x_{\mathrm{water}}+145 x_{\mathrm{ChCl}} x_{\mathrm{EtOH}}+108 x_{\mathrm{Glyc}} x_{\mathrm{water}}+129 x_{\mathrm{Glyc}} x_{\mathrm{EtOH}} \\
&+278 x_{\mathrm{water}} x_{\mathrm{EtOH}} \\
& \mathrm{m} D \mathrm{P}=6.21 x_{\mathrm{ChCl}}+ 7.87 x_{\mathrm{Glyc}}+4.49 x_{\mathrm{water}}+6.46 x_{\mathrm{EtOH}}+3.31 x_{\mathrm{water}} x_{\mathrm{EtOH}} \\
& \% \mathrm{Gal}=39.1 x_{\mathrm{ChCl}}+46.3 x_{\mathrm{Glyc}}+22.7 x_{\text {water }}+32.7 x_{\mathrm{EtOH}}-12.8 x_{\mathrm{ChCl}} x_{\mathrm{Glyc}}-22.7 x_{\mathrm{ChCl}} x_{\text {water }} \\
&+27.0 x_{\mathrm{Glyc}} x_{\mathrm{EtOH}}+48.3 x_{\mathrm{water}} x_{\mathrm{EtOH}}
\end{aligned}
$$

The performed ANOVA analysis revealed that the resulting models for $Y_{\mathrm{PAC}}, \mathrm{mDP}$ and $\%$ Gal all have $p$-values $<0.0001$, adjusted $r^{2}$ values of $0.92,0.94$ and 0.98 , respectively and predicted $r^{2}$ values of $0.82,0.92$ and 0.97 , respectively, indicating the statistical robustness of the resulting quadratic models.

From these models it can be concluded that, with respect to $Y_{\text {PAC }}$ (Figure $4 \mathrm{~A}$ ), $x_{\mathrm{ChCl}}, x_{\text {water }}$ and $x_{\mathrm{EtOH}}$ have an optimal value at $0.5,0.3$ and 0.2 , respectively and that $x_{\mathrm{Glyc}}$ has a detrimental effect on it. With this combination, the predicted values of $Y_{\mathrm{PAC}}, \mathrm{mDP}$ and $\% \mathrm{Gal}$ are $86.6 \mathrm{mg}_{\mathrm{PAC}} / \mathrm{g}_{\mathrm{BM}}, 6.0$ and $32.5 \%$, respectively which represents $91.7 \%$ of the $Y_{\mathrm{PAC}}$ obtained with AAE, a decrease in mDP, 8.1 and a similar \%Gal, 31.9\%. The validation runs resulted in a $Y_{\mathrm{PAC}}$ of $72.4 \mathrm{mg}$ PAC $/ \mathrm{g}_{\mathrm{BM}}, \mathrm{mDP}$ of 5.9 and $\% \mathrm{Gal}$ of $30.6 \%$ which are in a reasonable agreement with the predicted values, validating the models. Based on the results obtained for ESs, it is possible to conclude that AAE is a more suitable method for laboratory scale analysis, especially if solvent removal is considered.

Nevertheless, when compared to the conventional extraction process, HSE, an increase in $Y_{\text {PAC }}$ of $43.4 \%$ and higher mDP values, 6.0 in opposition to 3.5 is observed, which indicates the potential of the proposed system in replacing conventional methods on a purely $Y_{\mathrm{PAC}}$ basis.

If other aspects of the final extract are prioritized, namely $\mathrm{mDP}$ (Figure $4 \mathrm{~B}$ ) and \%Gal (Figure 4C), with this system, it is possible to achieve, with this system, values that can go as high as 7.37 and $47.1 \%$, respectively, while maintaining a $Y_{\mathrm{PAC}}$ of $72.2 \mathrm{mg}$ PAC $/ \mathrm{g}_{\mathrm{BM}}$. This can be achieved with $x_{\mathrm{Glyc}}$ $x_{\text {water }}$ and $x_{\mathrm{EtOH}}$ values of $0.68,0.05$ and 0.27 , respectively, which represents an increase of $19.5 \%$ in $Y_{\text {PAC }}$ when compared with the conventional extraction process, HSE. The validation runs resulted in a $Y_{\mathrm{PAC}}$ of $67.2 \mathrm{mg} \mathrm{PAC}_{\mathrm{P}} / \mathrm{g}_{\mathrm{BM}}, \mathrm{mDP}$ of 7.5 and $\% \mathrm{Gal}$ of $47.2 \%$ which are in a reasonable agreement with the values predicted by the model. This behavior is contrary to what would be expected, considering that PACs with a higher DP should be more difficult to extract and therefore an increase in $Y_{\text {PAC }}$ should be associated with an increase in $\mathrm{mDP}$ which was not verified, reinforcing the idea that this solvent composition is more specific for PACs with higher DP. 

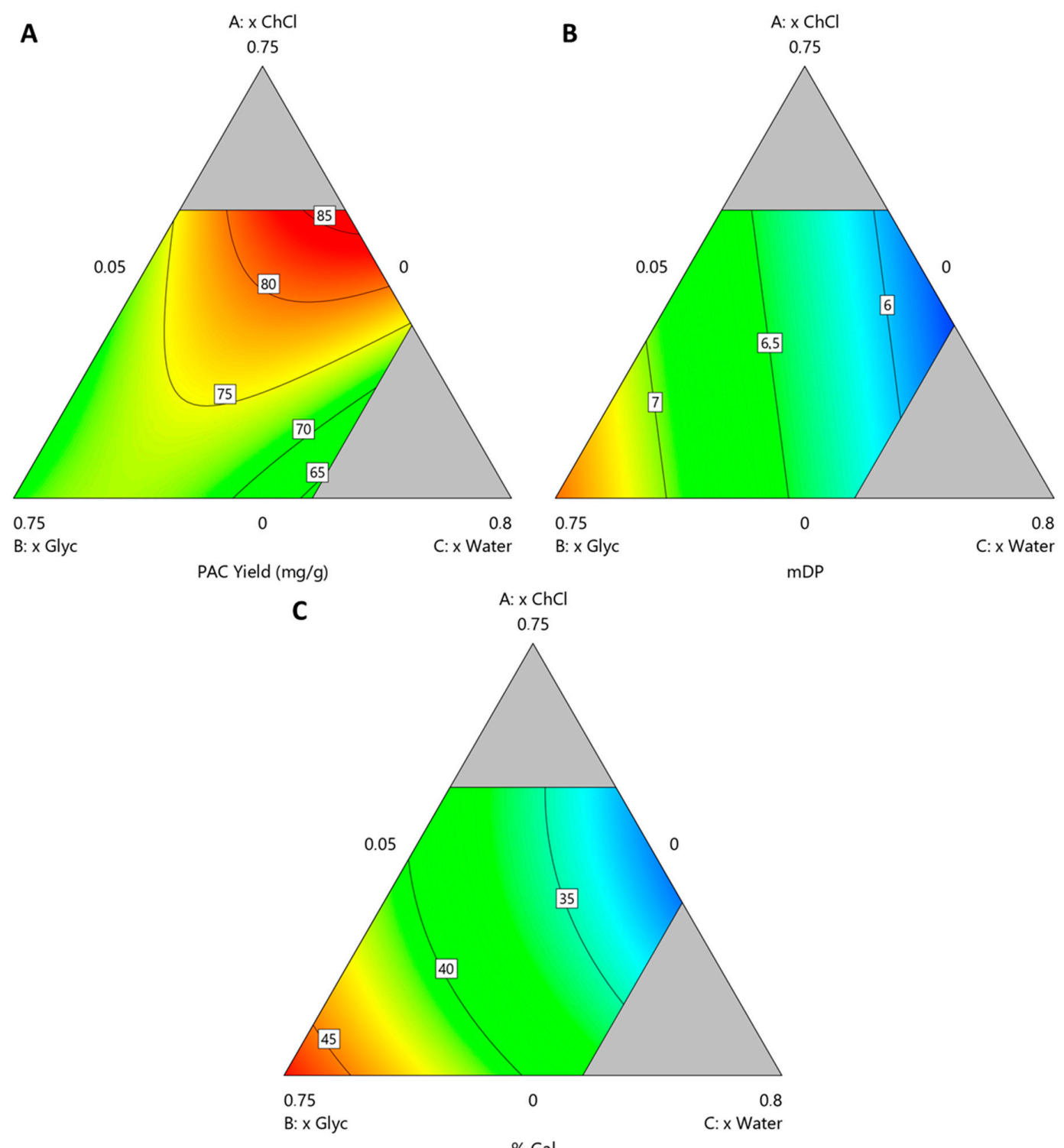

Figure 4. Contour plots obtained for solvent compostiion optimization at $x_{\mathrm{EtOH}}=0.2$ for (A) $Y_{\mathrm{PAC}}$, (B) $\mathrm{mDP}$ and (C) \%Gal.

\subsection{Determination of Optimal Extraction Conditions}

For the optimization of the extraction conditions, the solvent composition that resulted in a higher $Y_{\mathrm{PAC}}\left(x_{\mathrm{ChCl}}=0.5, x_{\text {water }}=0.3\right.$ and $\left.x_{\mathrm{EtOH}}=0.2\right)$ was chosen since $\mathrm{mDP}$ and $\% \mathrm{Gal}$ are still above what is obtained with HSE.

Consequently, a 15-run RSM experiment with Box-Behnken design was made where temperature, $\% \mathrm{BM}$ and extraction time were varied as specified in Table A2 and $Y_{\mathrm{PAC}}, \mathrm{mDP}$ and $\% \mathrm{Gal}$ were determined.

The resulting polynomials are presented in Equations (4)-(6) for $Y_{\mathrm{PAC}}, \mathrm{mDP}$ and $\% \mathrm{Gal}$, respectively, from which contour plots were derived and presented in Figure $5 \mathrm{~A}-\mathrm{F}$ where $\% \mathrm{BM}$ was kept constant at $14.4 \%$ in $\mathrm{A}, \mathrm{C}$ and $\mathrm{E}$ and extraction time was kept at $5 \mathrm{~h}$ in $\mathrm{B}, \mathrm{D}$ and $\mathrm{F}$.

$$
\begin{aligned}
Y_{\mathrm{PAC}}=-184+6.10 \text { temp }+ & 1.81 \%_{\mathrm{BM}}-2.30 \text { time }+0.338 \%_{\mathrm{BM}} \text { time }-0.0297 \mathrm{temp}^{2}-0.122 \%_{\mathrm{BM}}^{2} \\
\mathrm{mDP}=-0.0559+ & 0.0996 \text { temp }+0.140 \%{ }_{\mathrm{BM}}+0.430 \text { time }-0.00571 \text { temp time } \\
- & 0.000505 \text { temp }^{2}-0.00407 \%_{\mathrm{BM}}^{2}
\end{aligned}
$$




$$
\% \text { Gal }=28.3-0.0629 \text { temp }+0.794 \%{ }_{\mathrm{BM}}-0.0214 \%{ }_{\mathrm{BM}}^{2}
$$
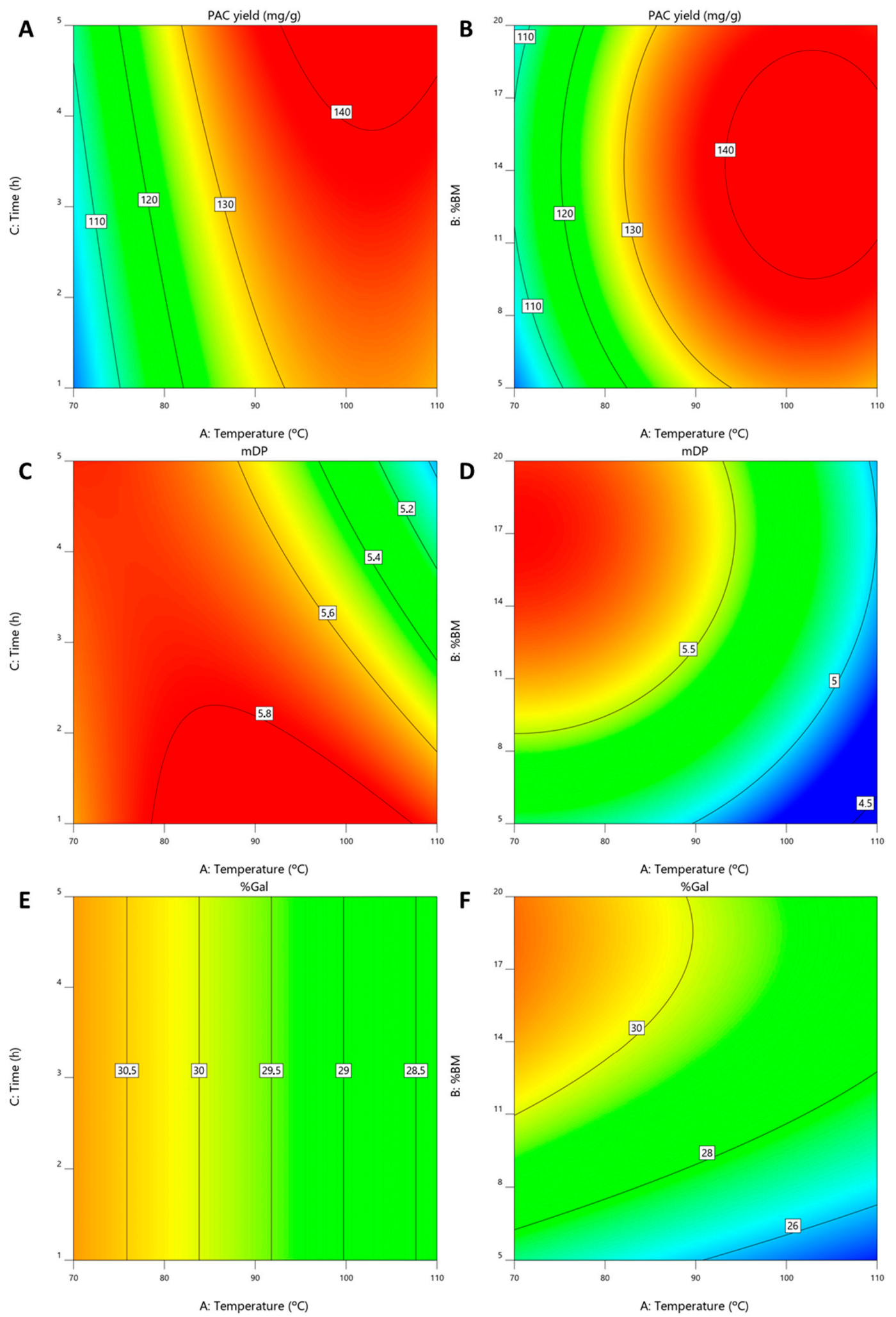

Figure 5. Contour plots obtained for extraction conditions optimization for (A,B) $Y_{\mathrm{PAC}},(\mathbf{C}, \mathbf{D}) \mathrm{mDP}$ and (E,F) \%Gal. 
The performed ANOVA analysis revealed that the resulting models for $Y_{\mathrm{PAC}}, \mathrm{mDP}$ and $\% \mathrm{Gal}$ have $p$-values of $0.0002,0.0007$ and $<0.0001$, respectively, adjusted $r^{2}$ values of $0.89,0.88$ and 0.89 , respectively and predicted $r^{2}$ values of $0.73,0.67$ and 0.82 , respectively, indicating the statistical robustness of the resulting quadratic models.

From these models, it can be concluded that the optimal $Y_{\text {PAC }}$ values are obtained with $14.4 \%(\mathrm{~m} / \mathrm{m})$ of BM, at $102.8^{\circ} \mathrm{C}$ for $5 \mathrm{~h}$ (Figure $5 \mathrm{~A}, \mathrm{~B}$ ). This resulted in predicted $Y_{\mathrm{PAC}}$ of $143.0 \mathrm{mg}_{\mathrm{PAC}} / \mathrm{g}_{\mathrm{BM}}, \mathrm{mDP}$ of 5.2 and \%Gal of $28.8 \%$ which despite representing a dramatic increase from what is obtained at $30{ }^{\circ} \mathrm{C}$ $(65 \%)$ and with HSE $(238 \%)$, also represents a decrease in mDP compared to the value obtained at $30{ }^{\circ} \mathrm{C}(6.0)$. The validation runs resulted in a $Y_{\mathrm{PAC}}$ of $144.1 \mathrm{mg}_{\mathrm{PAC}} / \mathrm{g}_{\mathrm{BM}}, \mathrm{mDP}$ of 6.0 and $\% \mathrm{Gal}$ of $28.3 \%$ which are in agreement with the model predictions.

In addition and even though the best results are obtained with $5 \mathrm{~h}$ of extraction time, this factor has a small impact on the overall $Y_{\text {PAC. }}$. Furthermore, if $\mathrm{mDP}$ is considered (Figure 5C) it becomes clear that at temperatures above $90{ }^{\circ} \mathrm{C}$, the increase in extraction time causes a decrease in $\mathrm{mDP}$, indicating thermal degradation of the PACs, which is in line with the results published by Ramos et al. [53].

With this in mind, the results can be improved considering both $Y_{\mathrm{PAC}}$ and $\mathrm{mDP}$ in which case the optimal conditions would be $99^{\circ} \mathrm{C}$ with $13.4 \%$ of biomass for $1 \mathrm{~h}$. In this situation the extraction process would have an $Y_{\mathrm{PAC}}$ of $133.6 \mathrm{mg}_{\mathrm{PAC}} / \mathrm{g}_{\mathrm{BM}}$ and would result in a final extract with a mDP of 5.9 and $\% \mathrm{Gal}$ of $28.8 \%$. These conditions are not optimal for $\mathrm{Y}_{\mathrm{PAC}}$ but would enable the obtention of an extract more similar to the one obtained at $30^{\circ} \mathrm{C}$ in terms of mDP. The confirmation runs resulted in a $Y_{\text {PAC }}$ of $125.9 \mathrm{mg}_{\mathrm{PAC}} / \mathrm{g}_{\mathrm{BM}}, \mathrm{mDP}$ of $6.5 \mathrm{and} \% \mathrm{Gal}$ of $29.6 \%$ which are in a reasonable agreement with what should be expected.

$\mathrm{mDP}$ also relates with the \%BM (Figure 5D), being possible to obtain higher mDP values at higher biomass concentrations which further indicates the selectivity of the quaternary solvent system towards PACs with higher DP. This conclusion is based on the fact that with an increase in biomass concentration one should expected an increase in compounds that are more easily extracted in detriment of others, in this case PACs with higher DP.

As far as \%Gal is concerned (Figure $5 \mathrm{E}, \mathrm{F}$ ), extraction time has no effect on the final result and, similarly to $\mathrm{mDP}$, an increase in \%Gal can be achieved with higher \%BM and lower temperatures, although this effect is less accentuated.

\section{Discussion}

In order to select the better HBA-HBD combination for the intended application, ESs stability and possible interactions with PACs must also be considered.

More specifically, if only $Y_{\mathrm{PAC}}$ is considered, the combination of $\mathrm{ChCl}$ and MalA would be considered the best candidate, as shown in Figure 3A. Especially, considering that this specific mixture and others alike have been extensively characterized and proposed as valid alternatives for biomass processing [54]. Unfortunately and as described elsewhere ESs composed by $\mathrm{ChCl}$ and MalA are not long term stable at room temperature and are negatively affected by temperature even in short incubation times [55]. These would limit considerably not only the process optimization by means of increased temperature but the possibility of recycling the solvent which might be necessary in order to develop a feasible industrial process.

Despite resulting in $Y_{\text {PAC }}$ that in some conditions are comparable to the ones obtained with MalA, ESs containing Ur give rise to extracts with low $\mathrm{mDP}$ and \%Gal. In addition, contrary to what happens with the other candidates, Ur does not work synergistically with ethanol that as shown before is an important factor for \%Gal tuning.

The use of Glu mixtures resulted in lower $Y_{\text {PAC }}$ with little effect on $\mathrm{mDP}$ and \%Gal. Nevertheless, Glu [56] and carbohydrate based [57] ESs have in general very high viscosity values which require the addition of considerable amounts of water in order to achieve reasonable viscosity levels. This in turn results, as discussed previously, in a reduction of the extraction efficiency and in a decrease in microbiological stability which makes solvent recycling not feasible. 
The mixture of $\mathrm{ChCl}$ with Glyc presents comparable values of $Y_{\mathrm{PAC}}$ and $\mathrm{mDP}$ to the ones obtained with Glu mixtures but lower \%Gal values. As in the case of MalA, Glyc-based solvents have been extensively described for biomass processing both in [51] and out [58] of the ES context. Additionally, Glyc is a cheap and abundant by-product obtained from biodiesel production that can be sustainably sourced [59] and is already largely used in food, medical and cosmetic industries due to its safety for human consumption. Recently, promising results were observed in the use of Glyc-based ES for the extraction of other flavonoids, namely apigenin, luteolin and quercetin from Satureja thymbra [60].

Considering the different $\mathrm{mDP}$ and $\% \mathrm{Gal}$ that were obtained with different component proportions of the proposed quaternary system, it can be inferred that by varying ESs composition it is possible to tune the final extract characteristics to specific values of $\mathrm{mDP}$ and \%Gal. More specifically, to values ranging from 5.95 to 7.37 for $\mathrm{mDP}$ and from 32.5 to $47.1 \%$ for $\% \mathrm{Gal}$, whilst maintaining an acceptable $Y_{\text {PAC }}$. Additionally, if the temperature difference between the conditions used in the solvent composition optimization assay $\left(30^{\circ} \mathrm{C}\right)$ and conventional extraction method, $\operatorname{HSE}\left(110^{\circ} \mathrm{C}\right)$, is considered a further increase in $Y_{\mathrm{PAC}}$ is to be expected.

The models developed here, in addition to allowing for the optimization of the process in terms of $Y_{\mathrm{PAC}}, \mathrm{mDP}$ and \%Gal, can also be used to minimize compositional differences in the final extract that derive from differences in the grape variety used as raw material [61] or different plant parts from the same variety [62], enabling the compositional normalization of the final extract and facilitating its implementation in industrial processes. If taken to its full potential these models could also be employed to minimize differences between two completely different sources [23] further facilitating the industrial implementation of PAC extracts in the context of circular economy.

\section{Conclusions}

ESs have recently increased their popularity in biomass processing and the work here presented further demonstrates the potential that this type of solvents has on the improvement of conventional methodologies. More specifically, herein it is described for the first time, at the best of our knowledge, the possibility of selectively improving the final extracts' content in PACs with higher degree of polymerization by means of a quaternary solvent system composed of choline chloride, glycerol, water and ethanol. Furthermore, it was shown that it is possible to tune the percentage of galloylated PACs to specific values by varying the mass fractions of the four components whilst not significantly compromising on the overall extraction yield.

In addition, the feasibility of using grape pomace as raw material for the extraction of PACs is further demonstrated reinforcing the role of by-products in the context of a circular economy.

Author Contributions: Conceptualization, R.T.N.; methodology, R.T.N.; writing —original draft preparation, R.T.N.; writing-review and editing, S.A.O.S., J.O. and A.J.D.S.; supervision, S.A.O.S., J.O. and A.J.D.S.; funding acquisition, A.J.D.S. All authors have read and agreed to the published version of the manuscript.

Funding: This research was funded by FCT/MCTES with the financial support to CICECO (UIDB/50011/2020 \& UIDP/50011/2020) and REQUIMTE (UIDB/50006/2020 \& UIDP/50006/2020), to J.O. investigator contract (IF/00225/2015), R.T.N. PhD grant (SFRH/BD/129174/2017) and S.A.O.S. researcher contract included in the "AgroForWealth" project (CENTRO-01-0145-FEDER-000001). The APC was funded by CICECO (UIDB/50011/2020 \& UIDP/50011/2020).

Conflicts of Interest: The authors declare no conflict of interest. 


\section{Abbreviations}

$\begin{array}{ll}\text { PAC } & \text { proanthocyanidin } \\ \text { (D)ES } & \text { (deep) eutectic solvent } \\ \text { HBA } & \text { hydrogen bond acceptor } \\ \text { HBD } & \text { hydrogen bond donor } \\ \text { mDP } & \text { mean degree of polymerization } \\ \text { \%Gal } & \text { galloylation percentage } \\ \text { HPLC } & \text { High-Performance Liquid Chromatography } \\ \text { DAD } & \text { Diode-Array Detector } \\ \text { HWE } & \text { hot water extraction } \\ \text { HSE } & \text { hot sulfite extraction } \\ \text { AAE } & \text { aqueous acetone extraction } \\ \text { AEE } & \text { aqueous ethanol extraction } \\ \text { BM } & \text { biomass } \\ \text { ChCl } & \text { choline chloride } \\ \text { Bet } & \text { betaine } \\ \text { Pro } & \text { proline } \\ \text { Ur } & \text { urea } \\ \text { MalA } & \text { malic acid } \\ \text { Glu } & \text { glucose } \\ \text { Glyc } & \text { Glycerol } \\ \text { RSM } & \text { Response Surface Methodology }\end{array}$

\section{Appendix A}

Table A1. Mass fractions of choline chloride, glycerol, water and ethanol used in optimization of solvent composition and respective measured and predicted values of $Y_{\mathrm{PAC}}, \mathrm{mDP}$ and $\% \mathrm{Gal}$.

\begin{tabular}{|c|c|c|c|c|c|c|c|c|c|c|}
\hline \multirow{2}{*}{ Run } & \multirow{2}{*}{$x_{\mathrm{ChCl}}$} & \multirow{2}{*}{$x_{\mathrm{Glyc}}$} & \multirow{2}{*}{$x_{\text {water }}$} & \multirow{2}{*}{$x_{\mathrm{EtOH}}$} & \multicolumn{2}{|c|}{$Y_{\mathrm{PAC}}\left(\mathrm{mg}_{\mathrm{PAC}} / \mathrm{g}_{\mathrm{BM}}\right)$} & \multicolumn{2}{|c|}{ mDP } & \multicolumn{2}{|c|}{$\%$ Gal } \\
\hline & & & & & Measured & Predicted & Measured & Predicted & Measured & Predicted \\
\hline 1 & 0 & 0.1 & 0.5 & 0.4 & 69.6 & 68.3 & 6.2 & 6.3 & 39.7 & 39.8 \\
\hline 2 & 0.263 & 0.316 & 0.05 & 0.371 & 75.7 & 74.5 & 6.5 & 6.8 & 40.7 & 40.9 \\
\hline 3 & 0.237 & 0.446 & 0.317 & 0 & 59.7 & 60.9 & 6.5 & 6.4 & 33.6 & 34.1 \\
\hline 4 & 0 & 0.5 & 0.5 & 0 & 48.7 & 49.2 & 6.3 & 6.2 & 34.8 & 34.5 \\
\hline 5 & 0 & 0.1 & 0.5 & 0.4 & 66.8 & 68.3 & 6.3 & 6.3 & 39.9 & 39.8 \\
\hline 6 & 0.54 & 0.25 & 0.05 & 0.16 & 72.5 & 74.2 & 6.8 & 6.6 & 38.3 & 38.2 \\
\hline 7 & 0 & 0.5 & 0.5 & 0 & 50.6 & 49.2 & 6.2 & 6.2 & 34.9 & 34.5 \\
\hline 8 & 0.3 & 0.04 & 0.26 & 0.4 & 84.1 & 84 & 6.5 & 6.3 & 36.5 & 36.1 \\
\hline 9 & 0 & 0.526 & 0.282 & 0.192 & 73.7 & 72.4 & 7.0 & 6.8 & 42.9 & 42.4 \\
\hline 10 & 0 & 0.95 & 0.05 & 0 & 57.4 & 59.8 & 7.7 & 7.7 & 44.9 & 45.1 \\
\hline 11 & 0.7 & 0 & 0.3 & 0 & 81.3 & 76.9 & 5.7 & 5.7 & 29.1 & 29.4 \\
\hline 12 & 0.104 & 0.699 & 0.05 & 0.147 & 68.5 & 68 & 7.2 & 7.4 & 43.9 & 44.5 \\
\hline 13 & 0 & 0.55 & 0.05 & 0.4 & 72.2 & 71.5 & 7.2 & 7.2 & 47.3 & 46.6 \\
\hline 14 & 0 & 0.95 & 0.05 & 0 & 61.5 & 59.8 & 7.5 & 7.7 & 44.5 & 45.1 \\
\hline 15 & 0.401 & 0 & 0.5 & 0.099 & 72.4 & 71.5 & 5.6 & 5.5 & 28.9 & 28.1 \\
\hline 16 & 0.378 & 0.552 & 0.07 & 0 & 60.5 & 58.6 & 7.0 & 7.0 & 39.4 & 38.7 \\
\hline 17 & 0 & 0.55 & 0.05 & 0.4 & 69.7 & 71.5 & 7.4 & 7.2 & 46.5 & 46.6 \\
\hline 18 & 0.147 & 0.231 & 0.5 & 0.122 & 61.9 & 63.2 & 5.7 & 6.0 & 31.8 & 33.4 \\
\hline 19 & 0.459 & 0.235 & 0.306 & 0 & 65.5 & 66.7 & 6.0 & 6.1 & 31.6 & 31.2 \\
\hline 20 & 0.7 & 0 & 0.3 & 0 & 73.3 & 76.9 & 5.7 & 5.7 & 29.3 & 29.4 \\
\hline
\end{tabular}

$Y_{\mathrm{PAC}}$ - proanthocyanidin yield, $\mathrm{mDP}$ - mean degree of polymerization, \%Gal—galloylation percentage. 
Table A2. Temperature, biomass percentage and time used in the optimization of extraction conditions and respective measured and predicted values of $Y_{\mathrm{PAC}}, \mathrm{mDP}$ and $\% \mathrm{Gal}$.

\begin{tabular}{|c|c|c|c|c|c|c|c|c|c|}
\hline \multirow{2}{*}{ Run } & \multirow{2}{*}{ Temp $\left({ }^{\circ} \mathrm{C}\right)$} & \multirow{2}{*}{$\%$ BM } & \multirow{2}{*}{ Time (h) } & \multicolumn{2}{|c|}{$Y_{\text {PAC }}\left(\mathrm{mg}_{\mathrm{PAC}} / \mathrm{g}_{\mathrm{BM}}\right)$} & \multicolumn{2}{|c|}{$\mathrm{mDP}$} & \multicolumn{2}{|c|}{$\%$ Gal } \\
\hline & & & & Measured & Predicted & Measured & Predicted & Measured & Predicted \\
\hline 1 & 90 & 20 & 1 & 111.9 & 116.5 & 5.8 & 5.9 & 30.6 & 29.9 \\
\hline 2 & 90 & 12.5 & 3 & 131.8 & 133.8 & 5.8 & 5.7 & 28.8 & 29.2 \\
\hline 3 & 90 & 12.5 & 3 & 134.0 & 133.8 & 5.5 & 5.7 & 29.0 & 29.2 \\
\hline 4 & 90 & 5 & 5 & 130.4 & 127.4 & 5.1 & 5.0 & 26.0 & 26.6 \\
\hline 5 & 110 & 20 & 3 & 130.4 & 128.7 & 5.4 & 5.4 & 28.2 & 28.7 \\
\hline 6 & 90 & 20 & 5 & 133.1 & 134.3 & 5.7 & 5.6 & 29.0 & 29.9 \\
\hline 7 & 110 & 12.5 & 5 & 133.6 & 141.0 & 4.8 & 4.9 & 28.4 & 27.9 \\
\hline 8 & 70 & 12.5 & 1 & 102.3 & 102.9 & 5.7 & 5.6 & 30.5 & 30.5 \\
\hline 9 & 70 & 12.5 & 5 & 113.2 & 110.6 & 5.7 & 5.7 & 30.4 & 30.5 \\
\hline 10 & 70 & 20 & 3 & 102.4 & 98.3 & 5.7 & 5.7 & 32.0 & 31.2 \\
\hline 11 & 90 & 5 & 1 & 129.5 & 129.8 & 5.3 & 5.3 & 27.1 & 26.1 \\
\hline 12 & 70 & 5 & 3 & 95.6 & 101.6 & 5.1 & 5.1 & 26.6 & 27.3 \\
\hline 13 & 90 & 12.5 & 3 & 138.7 & 133.8 & 5.6 & 5.7 & 28.7 & 29.2 \\
\hline 14 & 110 & 5 & 3 & 135.2 & 131.9 & 4.8 & 4.8 & 24.5 & 24.8 \\
\hline 15 & 110 & 12.5 & 1 & 135.8 & 133.3 & 5.7 & 5.7 & 28.3 & 27.9 \\
\hline
\end{tabular}

$Y_{\text {PAC }}$-proanthocyanidin yield, mDP—-mean degree of polymerization, \%Gal—galloylation percentage.

Table A3. Experimental values of $Y_{\mathrm{PAC}}, \mathrm{mDP}$ and \%Gal obtained with conventional solvents.

\begin{tabular}{cccc}
\hline Solvent & $\boldsymbol{\Upsilon}_{\text {PAC }}\left(\mathbf{m g}_{\mathbf{P A C}} / \mathbf{g}_{\mathbf{B M}}\right)$ & $\mathbf{m D P}$ & \%Gal \\
\hline HWE & $11.5 \pm 1.0$ & $2.7 \pm 0.01$ & $13.8 \pm 0.7$ \\
HSE & $1.4 \pm 0.1$ & $3.5 \pm 0.04$ & $26.9 \pm 0.3$ \\
AAE & $91.5 \pm 3.0$ & $8.1 \pm 0.04$ & $31.9 \pm 0.3$ \\
AEE15 & $18.9 \pm 0.7$ & $4.9 \pm 0.08$ & $24.4 \pm 0.1$ \\
AEE30 & $39.7 \pm 1.2$ & $5.9 \pm 0.08$ & $29.6 \pm 0.2$ \\
AEE50 & $46.7 \pm 1.8$ & $5.9 \pm 0.30$ & $37.0 \pm 0.7$ \\
AEE70 & $45.3 \pm 0.6$ & $6.1 \pm 0.12$ & $41.6 \pm 0.6$ \\
\hline
\end{tabular}

$Y_{\mathrm{PAC}}$ - proanthocyanidin yield, $\mathrm{mDP}$ - mean degree of polymerization, \%Gal—galloylation percentage; HWE-hot water extraction; HSE-hot sulfite extraction; AAE—aqueous acetone extraction; AEEx—aqueous ethanol extraction.

\section{References}

1. Abbas, M.; Saeed, F.; Anjum, F.M.; Afzaal, M.; Tufail, T.; Bashir, M.S.; Ishtiaq, A.; Hussain, S.; Suleria, H.A.R. Natural polyphenols: An overview. Int. J. Food Prop. 2017, 20, 1689-1699. [CrossRef]

2. González De Colmenares, N.; Ramírez-Martínez, J.R.; Aldana, J.O.; Ramos-Niño, M.E.; Clifford, M.N.; Pékerar, S.; Méndez, B. Isolation, characterisation and determination of biological activity of coffee proanthocyanidins. J. Sci. Food Agric. 1998, 77, 368-372. [CrossRef]

3. Scalbert, A. Antimicrobial properties of tannins. Phytochemistry 1991, 30, 3875-3883. [CrossRef]

4. Bernays, E.A. Tannins: An Alternative Viewpoint. Entomol. Exp. Appl. 1978, 24, 244-253. [CrossRef]

5. Barbehenn, R.V.; Peter Constabel, C. Tannins in plant-herbivore interactions. Phytochemistry 2011, 72, 1551-1565. [CrossRef]

6. House, W.A. Trace element bioavailability as exemplified by iron and zinc. J. Agric. Food Chem. 2004, 18, 174-181. [CrossRef]

7. Rinaldi, A.; Gambuti, A.; Moio, L. Application of the SPI (Saliva Precipitation Index) to the evaluation of red wine astringency. Food Chem. 2012, 135, 2498-2504. [CrossRef]

8. Barrett, A.H.; Farhadi, N.F.; Smith, T.J. Slowing starch digestion and inhibiting digestive enzyme activity using plant flavanols/tannins-A review of efficacy and mechanisms. LWT Food Sci. Technol. 2018, 87, 394-399. [CrossRef] 
9. Romer, F.H.; Underwood, A.P.; Senekal, N.D.; Bonnet, S.L.; Duer, M.J.; Reid, D.G.; Van Der Westhuizen, J.H. Tannin fingerprinting in vegetable tanned leather by solid state NMR spectroscopy and comparison with leathers tanned by other processes. Molecules 2011, 16, 1240-1252. [CrossRef]

10. Abdullah, U.H.B.; Pizzi, A. Tannin-furfuryl alcohol wood panel adhesives without formaldehyde. Eur. J. Wood Wood Prod. 2013, 71, 131-132. [CrossRef]

11. Vazallo-Valleumbrocio, G.; Medel-Marabolí, M.; Peña-Neira, Á.; López-Solís, R.; Obreque-Slier, E. Commercial enological tannins: Characterization and their relative impact on the phenolic and sensory composition of Carménère wine during bottle aging. LWT Food Sci. Technol. 2017, 83, 172-183. [CrossRef]

12. Libera, J.; Latoch, A.; Wójciak, K.M. Utilization of grape seed extract as a natural antioxidant in the technology of meat products inoculated with a probiotic strain of lab. Foods 2020, 9, 103. [CrossRef]

13. Qi, Y.; Zhang, H.; Wu, G.; Zhang, H.; Gu, L.; Wang, L.; Qian, H.; Qi, X. Mitigation effects of proanthocyanidins with different structures on acrylamide formation in chemical and fried potato crisp models. Food Chem. 2018, 250, 98-104. [CrossRef] [PubMed]

14. Anastasiadi, M.; Chorianopoulos, N.G.; Nychas, G.J.E.; Karoutounian, S.A. Antilisterial activities of polyphenol-rich extracts of grapes and vinification byproducts. J. Agric. Food Chem. 2009, 57, 457-463. [CrossRef] [PubMed]

15. Kessy, H.N.E.; Wang, K.; Zhao, L.; Zhou, M.; Hu, Z. Enrichment and biotransformation of phenolic compounds from litchi pericarps with angiotensin I-converting enzyme (ACE) inhibition activity. LWT Food Sci. Technol. 2018, 87, 301-309. [CrossRef]

16. Chen, X.; Xiong, J.; He, Q.; Wang, F. Characterization and potential antidiabetic activity of proanthocyanidins from the barks of Acacia mangium and Larix gmelinii. J. Chem. 2019, 2019, 1-9. [CrossRef]

17. Zhou, P.; Zhang, L.; Li, W.; Zhang, S.; Luo, L.; Wang, J.; Sun, B. In vitro evaluation of the anti-digestion and antioxidant effects of grape seed procyanidins according to their degrees of polymerization. J. Funct. Foods 2018, 49, 85-95. [CrossRef]

18. Zhong, H.; Xue, Y.; Lu, X.; Shao, Q.; Cao, Y.; Wu, Z.; Chen, G. The effects of different degrees of procyanidin polymerization on the nutrient absorption and digestive enzyme activity in mice. Molecules 2018, 23, 2916. [CrossRef]

19. Pierini, R.; Kroon, P.A.; Guyot, S.; Ivory, K.; Johnson, I.T.; Belshaw, N.J. Procyanidin effects on oesophageal adenocarcinoma cells strongly depend on flavan-3-ol degree of polymerization. Mol. Nutr. Food Res. 2008, 52, 1399-1407. [CrossRef]

20. Fu, Y.U.; Ye, X.; Lee, M.; Rankin, G.; Chen, Y.C. Prodelphinidins isolated from chinese bayberry leaves induces apoptosis via the p53-dependent signaling pathways in OVCAR-3 human ovarian cancer cells. Oncol. Lett. 2017, 13, 3210-3218. [CrossRef]

21. Bitzer, Z.T.; Glisan, S.L.; Dorenkott, M.R.; Goodrich, K.M.; Ye, L.; O’Keefe, S.F.; Lambert, J.D.; Neilson, A.P. Cocoa procyanidins with different degrees of polymerization possess distinct activities in models of colonic inflammation. J. Nutr. Biochem. 2015, 26, 827-831. [CrossRef] [PubMed]

22. Panzella, L.; Moccia, F.; Toscanesi, M.; Trifuoggi, M.; Giovando, S.; Napolitano, A. Exhausted woods from tannin extraction as an unexplored waste biomass: Evaluation of the antioxidant and pollutant adsorption properties and activating effects of hydrolytic treatments. Antioxidants 2019, 8, 84. [CrossRef] [PubMed]

23. Neto, R.T.; Santos, S.A.O.; Oliveira, J.; Silvestre, A.J.D. Biorefinery of high polymerization degree proanthocyanidins in the context of circular economy. Ind. Crop. Prod. 2020, 151, 112450. [CrossRef]

24. European Parliament and Council Directive 2008/98/EC of the European Parliament and of the Council of 19 November 2008 on waste and repealing certain directives. Off. J. Eur. Union 2008, 3-30.

25. Qu, W.; Shi, S.; Li, P.; Pan, Z.; Venkitasamy, C. Extraction kinetics and properties of proanthocyanidins from pomegranate peel. Int. J. Food Eng. 2014, 10, 683-695. [CrossRef]

26. Bianchi, S.; Kroslakova, I.; Janzon, R.; Mayer, I.; Saake, B.; Pichelin, F. Characterization of condensed tannins and carbohydrates in hot water bark extracts of European softwood species. Phytochemistry 2015, 120, 53-61. [CrossRef]

27. Hassan, Y.I.; Kosir, V.; Yin, X.; Ross, K.; Diarra, M.S. Grape Pomace as a Promising Antimicrobial Alternative in Feed: A Critical Review. J. Agric. Food Chem. 2019, 67, 9705-9718. [CrossRef]

28. Averilla, J.N.; Oh, J.; Kim, H.J.; Kim, J.S.; Kim, J.S. Potential health benefits of phenolic compounds in grape processing by-products. Food Sci. Biotechnol. 2019, 28, 1607-1615. [CrossRef] 
29. Tayengwa, T.; Mapiye, C. Citrus and winery wastes: Promising dietary supplements for sustainable ruminant animal nutrition, health, production, and meat quality. Sustainability 2018, 10, 3718. [CrossRef]

30. International Organisation of Vine and Wine; Intergovernmental Organisation. 2019 Statistical Report on World Vitiviniculture. Available online: http://oiv.int/public/medias/6782/oiv-2019-statistical-report-onworld-vitiviniculture.pdf (accessed on 17 October 2020).

31. Sealy-Fisher, V.J.; Pizzi, A. Increased pine tannins extraction and wood adhesives development by phlobaphenes minimization. Holz Als Roh Und Werkst. 1992, 50, 212-220. [CrossRef]

32. Hellström, J.K.; Mattila, P.H. HPLC determination of extractable and unextractable proanthocyanidins in plant materials. J. Agric. Food Chem. 2008, 56, 7617-7624. [CrossRef] [PubMed]

33. Bianchi, S.; Koch, G.; Janzon, R.; Mayer, I.; Saake, B.; Pichelin, F. Hot water extraction of Norway spruce (Picea abies [Karst.]) bark: Analyses of the influence of bark aging and process parameters on the extract composition. Holzforschung 2016, 70, 619-631. [CrossRef]

34. Jablonský, M.; Škulcová, A.; Malvis, A.; Šima, J. Extraction of value-added components from food industry based and agro-forest biowastes by deep eutectic solvents. J. Biotechnol. 2018, 282, 46-66. [CrossRef] [PubMed]

35. Abbott, A.P.; Capper, G.; Davies, D.L.; Rasheed, R.K.; Tambyrajah, V. Novel solvent properties of choline chloride/urea mixtures. Chem. Commun. 2003, 70-71. [CrossRef] [PubMed]

36. Martins, M.A.R.; Pinho, S.P.; Coutinho, J.A.P. Insights into the nature of eutectic and deep eutectic mixtures. J. Solut. Chem. 2018. [CrossRef]

37. Cao, J.; Chen, L.; Li, M.; Cao, F.; Zhao, L.; Su, E. Efficient extraction of proanthocyanidin from Ginkgo biloba leaves employing rationally designed deep eutectic solvent-water mixture and evaluation of the antioxidant activity. J. Pharm. Biomed. Anal. 2018, 158, 317-326. [CrossRef]

38. Syed, U.T.; Brazinha, C.; Crespo, J.G.; Ricardo-da-Silva, J.M. Valorisation of grape pomace: Fractionation of bioactive flavan-3-ols by membrane processing. Sep. Purif. Technol. 2017, 172, 404-414. [CrossRef]

39. Chu, M.J.; Du, Y.M.; Liu, X.M.; Yan, N.; Wang, F.Z.; Zhang, Z.F. Extraction of proanthocyanidins from Chinese wild rice (Zizania latifolia) and analyses of structural composition and potential bioactivities of different fractions. Molecules 2019, 24, 1681. [CrossRef]

40. Zhang, Y.; Zhou, X.; Tao, W.; Li, L.; Wei, C.; Duan, J.; Chen, S.; Ye, X. Antioxidant and antiproliferative activities of proanthocyanidins from Chinese bayberry (Myrica rubra Sieb. et Zucc.) leaves. J. Funct. Foods 2016, 27, 645-654. [CrossRef]

41. Harbertson, J.F.; Kilmister, R.L.; Kelm, M.A.; Downey, M.O. Impact of condensed tannin size as individual and mixed polymers on bovine serum albumin precipitation. Food Chem. 2014, 160, 16-21. [CrossRef] [PubMed]

42. Zeller, W.E.; Sullivan, M.L.; Mueller-Harvey, I.; Grabber, J.H.; Ramsay, A.; Drake, C.; Brown, R.H. Protein precipitation behavior of condensed tannins from Lotus pedunculatus and Trifolium repens with different mean degrees of polymerization. J. Agric. Food Chem. 2015, 63, 1160-1168. [CrossRef] [PubMed]

43. Derksen, A.; Hensel, A.; Hafezi, W.; Herrmann, F.; Schmidt, T.J.; Ehrhardt, C.; Ludwig, S.; Kühn, J. 3-O-galloylated procyanidins from Rumex acetosa L. inhibit the attachment of influenza A virus. PLoS ONE 2014, 9. [CrossRef] [PubMed]

44. Rinaldi, A.; Jourdes, M.; Teissedre, P.L.; Moio, L. A preliminary characterization of Aglianico (Vitis vinifera L. cv.) grape proanthocyanidins and evaluation of their reactivity towards salivary proteins. Food Chem. 2014, 164, 142-149. [CrossRef] [PubMed]

45. Lizarraga, D.; Lozano, C.; Briedé, J.J.; Van Delft, J.H.; Touriño, S.; Centelles, J.J.; Torres, J.L.; Cascante, M. The importance of polymerization and galloylation for the antiproliferative properties of procyanidin-rich natural extracts. FEBS J. 2007, 274, 4802-4811. [CrossRef] [PubMed]

46. Alwerdt, J.L.; Seigler, D.S.; De Mejia, E.G.; Yousef, G.G.; Lila, M.A. Influence of alternative liquid chromatography techniques on the chemical complexity and bioactivity of isolated proanthocyanidin mixtures. J. Agric. Food Chem. 2008, 56, 1896-1906. [CrossRef] [PubMed]

47. Porter, L.J.; Hrstich, L.N.; Chan, B.G. The conversion of procyanidins and prodelphinidins to cyanidin and delphinidin. Phytochemistry 1985, 25, 223-230. [CrossRef]

48. Kennedy, J.A.; Jones, G.P. Analysis of proanthocyanidin cleavage products following acid-catalysis in the presence of excess phloroglucinol. J. Agric. Food Chem. 2001, 49, 1740-1746. [CrossRef] 
49. Ramos, P.A.B.; Santos, S.A.O.; Guerra, Â.R.; Guerreiro, O.; Freire, C.S.R.; Rocha, S.M.; Duarte, M.F.; Silvestre, A.J.D. Phenolic composition and antioxidant activity of different morphological parts of Cynara cardunculus L. var. altilis (DC). Ind. Crops Prod. 2014, 61, 460-471. [CrossRef]

50. Tang, X.; Zuo, M.; Li, Z.; Liu, H.; Xiong, C.; Zeng, X.; Sun, Y.; Hu, L.; Liu, S.; Lei, T.; et al. Green Processing of Lignocellulosic Biomass and Its Derivatives in Deep Eutectic Solvents. ChemSusChem 2017, 10, 2696-2706. [CrossRef]

51. Alomar, M.K.; Hayyan, M.; Alsaadi, M.A.; Akib, S.; Hayyan, A.; Hashim, M.A. Glycerol-based deep eutectic solvents: Physical properties. J. Mol. Liq. 2016, 215, 98-103. [CrossRef]

52. Chen, Y.; Mu, T. Application of deep eutectic solvents in biomass pretreatment and conversion. Green Energy Environ. 2019, 4, 95-115. [CrossRef]

53. Ramos, V.; Bocalandro, C.; Riquelme, S.; Sanhueza, V.; Aspé, E.; Roeckel, M.; Fernández, K. Effect of the bench scale extraction conditions on Pinus radiata bark extract yield, antioxidant properties and composition. Maderas. Cienc. Y Tecnol. 2013, 15, 31-44. [CrossRef]

54. Radošević, K.; Ćurko, N.; Gaurina Srček, V.; Cvjetko Bubalo, M.; Tomašević, M.; Kovačević Ganić, K.; Radojčić Redovniković, I. Natural deep eutectic solvents as beneficial extractants for enhancement of plant extracts bioactivity. LWT Food Sci. Technol. 2016, 73, 45-51. [CrossRef]

55. Rodriguez Rodriguez, N.; Van Den Bruinhorst, A.; Kollau, L.J.B.M.; Kroon, M.C.; Binnemans, K. Degradation of Deep-Eutectic Solvents Based on Choline Chloride and Carboxylic Acids. ACS Sustain. Chem. Eng. 2019, 7, 11521-11528. [CrossRef]

56. Hayyan, A.; Mjalli, F.S.; Alnashef, I.M.; Al-Wahaibi, Y.M.; Al-Wahaibi, T.; Hashim, M.A. Glucose-based deep eutectic solvents: Physical properties. J. Mol. Liq. 2013, 178, 137-141. [CrossRef]

57. Silva, L.P.; Fernandez, L.; Conceiçao, J.H.F.; Martins, M.A.R.; Sosa, A.; Ortega, J.; Pinho, S.P.; Coutinho, J.A.P. Design and Characterization of Sugar-Based Deep Eutectic Solvents Using Conductor-like Screening Model for Real Solvents. ACS Sustain. Chem. Eng. 2018, 6, 10724-10734. [CrossRef]

58. García, J.I.; García-Marín, H.; Pires, E. Glycerol based solvents: Synthesis, properties and applications. Green Chem. 2014, 16, 1007-1033. [CrossRef]

59. Bewley, B.R.; Berkaliev, A.; Henriksen, H.; Ball, D.B.; Ott, L.S. Waste glycerol from biodiesel synthesis as a component in deep eutectic solvents. Fuel Process. Technol. 2015, 138, 419-423. [CrossRef]

60. Jancheva, M.; Grigorakis, S.; Loupassaki, S.; Makris, D.P. Optimised extraction of antioxidant polyphenols from Satureja thymbra using newly designed glycerol-based natural low-transition temperature mixtures (LTTMs). J. Appl. Res. Med. Aromat. Plants 2017, 6, 31-40. [CrossRef]

61. González-Centeno, M.R.; Jourdes, M.; Femenia, A.; Simal, S.; Rosselló, C.; Teissedre, P.L. Proanthocyanidin composition and antioxidant potential of the stem winemaking byproducts from 10 different grape varieties (Vitis vinifera L.). J. Agric. Food Chem. 2012, 60, 11850-11858. [CrossRef] [PubMed]

62. Vivas, N.; Nonier, M.-F.; de Gaulejac, N.V.; Absalon, C.; Bertrand, A.; Mirabel, M. Differentiation of proanthocyanidin tannins from seeds, skins and stems of grapes (Vitis vinifera) and heartwood of Quebracho (Schinopsis balansae) by matrix-assisted laser desorption/ionization time-of-flight mass spectrometry and thioacido. Anal. Chim. Acta 2004, 513, 247-256. [CrossRef]

Publisher's Note: MDPI stays neutral with regard to jurisdictional claims in published maps and institutional affiliations.

(C) 2020 by the authors. Licensee MDPI, Basel, Switzerland. This article is an open access article distributed under the terms and conditions of the Creative Commons Attribution (CC BY) license (http://creativecommons.org/licenses/by/4.0/). 